\title{
Phosphorylation of Tau by Fyn: Implications for Alzheimer's Disease
}

\author{
Gloria Lee, ${ }^{1}$ Ramasamy Thangavel, ${ }^{2}$ Vandana M. Sharma, ${ }^{1}$ Joel M. Litersky, ${ }^{1}$ Kiran Bhaskar, ${ }^{1}$ Sandy M. Fang, ${ }^{1}$ \\ Lana H. Do, ${ }^{1}$ Athena Andreadis, ${ }^{4}$ Gary Van Hoesen, ${ }^{2}$ and Hanna Ksiezak-Reding ${ }^{3}$ \\ Departments of ${ }^{1}$ Internal Medicine and ${ }^{2}$ Anatomy and Cell Biology, University of Iowa, Roy J. and Lucille A. Carver College of Medicine, Iowa City, Iowa \\ 52242, ${ }^{3}$ Department of Psychiatry, Mount Sinai School of Medicine, New York, New York 10029, and ${ }^{4}$ Department of Biomedical Sciences, Shriver Center, \\ University of Massachusetts Medical School, Waltham, Massachusetts 02452
}

The abnormal phosphorylation of tau protein on serines and threonines is a hallmark characteristic of the neurofibrillary tangles of Alzheimer's disease $(\mathrm{AD})$. The discovery that tau could be phosphorylated on tyrosine and evidence that $\mathrm{A} \beta$ signal transduction involved tyrosine phosphorylation led us to question whether tyrosine phosphorylation of tau occurred during the neurodegenerative process. In this study we determined that human tau tyr 18 was phosphorylated by the src family tyrosine kinase fyn. By developing both polyclonal and monoclonal probes specific for phospho-tyr18, we found that the phosphorylation of tau at tyr18 occurred at early developmental stages in mouse but was absent in the adult. Our phosphospecific probes also revealed that paired helical filament preparations exhibited phospho-tyr18 reactivity that was sensitive to phosphotyrosine-specific protein phosphatase treatment. Moreover, immunocytochemical studies indicated that tyrosine phosphorylated tau was present in the neurofibrillary tangles in AD brain. However, the staining pattern excluded neuropil threads and dystrophic neurites indicating that tyrosine phosphorylated tau was distributed in AD brain in a manner dissimilar from other abnormally phosphorylated tau. We also found evidence suggesting that differentially phosphorylated tau existed within degenerating neurons. Our data add new support for a role for fyn in the neurodegenerative process.

Key words: tau; fyn; tyrosine phosphorylation; neurofibrillary tangles; phosphospecific antibodies; Alzheimer's disease

\section{Introduction}

A prominent component of the neurofibrillary tangles of Alzheimer's disease $(\mathrm{AD})$ is the microtubule-associated protein tau. A primary characteristic of tau in $\mathrm{AD}$ is the presence of several phosphorylated serines and threonines that are less abundant in normal adult brain tau. Previously, we reported that tau is tyrosine phosphorylated when cotransfected with fyn (Lee et al., 1998), a src family tyrosine kinase that has a role during the development of the nervous system (for review, see Maness, 1992; Thomas and Brugge, 1997). The possible relevance of fyn to neurodegeneration has been suggested by Wood and coworkers, reporting that neuritic plaques and dystrophic neurites in $\mathrm{AD}$ brain contained phosphotyrosine (Wood and Zinsmeister, 1991) and that fyn was upregulated in a subset of neurons that also stained for abnormally phosphorylated tau (Shirazi and Wood, 1993). In addition, several other studies have suggested a role for tyrosine

\footnotetext{
Received Sept. 10, 2003; revised Jan. 12, 2004; accepted Jan. 12, 2004.

This work was supported by National Institutes of Health Grant AG17753. We thank Linette Fung and S. Todd Newman for technical support during the early stages of this study. We also thank Dr. Peter Davies for advice regarding the preparation of phosphorylation-specific antibodies and Drs. Charles Lovig of the University of lowa Hybridoma Facility, Brian Morrison of the University of lowa Molecular Analysis Facility, and Jimmy Page of BIAcore, Inc. for their expert help. We gratefully acknowledge the generous gifts of antibodies from Drs. Lester Binder, Gai Johnson, and Virginia Lee. We also thank Peleg Horowitz for critical reading of this manuscript and Paul Reimann for help with photography.

Correspondence should be addressed to Gloria Lee, 500 Newton Road, 17 MRC, lowa City, IA 52242. E-mail: gloria-lee@uiowa.edu.

D0I:10.1523/JNEUROSCI.4162-03.2004

Copyright $\odot 2004$ Society for Neuroscience $\quad$ 0270-6474/04/242304-09\$15.00/0
}

phosphorylation in $\mathrm{AD}$. $\mathrm{AD}$ brains showed an increase in phosphotyrosine-containing proteins (Shapiro et al., 1991), and cultured cells exposed to $A \beta$ contained higher levels of tyrosine phosphorylated proteins (Luo et al., 1995; Moore et al., 2002; Bamberger et al., 2003; Grace and Busciglio, 2003). Tyrosine phosphorylation of paxillin (Grace and Busciglio, 2003), tau (Williamson et al., 2002), and several protein kinases, including focal adhesion kinase (Zhang et al., 1994; Williamson et al., 2002), MAP kinase (Sato et al., 1997), and phosphatidylinositol 3-kinase (Luo et al., 1996), increase in the presence of A $\beta$. Moreover, signaling cascades initiated by $\mathrm{A} \beta$ in microglial cells have been shown to require fyn (Moore et al., 2002). Most interestingly, the involvement of fyn in neurodegeneration is supported by the finding that fyn negative cells are protected against $\mathrm{A} \beta$ induced neurotoxicity (Lambert et al., 1998). The fact that taunegative cells are also protected against $\mathrm{A} \beta$-induced neurotoxicity (Rapoport et al., 2002) makes it tempting to speculate that the fyn-tau interaction has a role in the neurodegenerative process.

Here, we investigate the tyrosine phosphorylation of tau by fyn. By identifying the tau residue that is tyrosine phosphorylated by fyn and developing phosphospecific probes for this site, we establish the presence of tyrosine phosphorylated tau in AD.

\section{Materials and Methods}

COS7 and $3 T 3$ cell transfections, immunoprecipitations, and immunofluorescence. Plasmids expressing full-length human tau, green fluorescent protein (GFP)-tau, fyn, and N-terminal fragments of tau have been previously described (Lee and Rook, 1992; Hall et al., 1997). Tau-GFP plas- 
mid was constructed through a modification of the pGFP-C2 vector (Clontech, Palo Alto, CA) using standard techniques. The GFP moiety was first excised using NheI-BglII; the vector ends were blunted then joined by blunt end ligation. GFP was then amplified by PCR and inserted into a KpnI-Bsp120I digested vector. Human tau (352 residue isoform) was amplified by PCR and inserted into the vector with a blunt end ligation at the amino end and a $K p n I$ site at the carboxy end, fusing it in frame with the GFP at the KpnI site (vector had been digested with HindIII, filled in, then digested with $K p n \mathrm{I})$. Tyrosine to phenylalanine replacements in tau (Y18F and Y29F) were made using the Stratagene ( $\mathrm{La}$ Jolla, CA) QuikChange Site-Directed Mutagenesis kit.

COS7 cell transfections were performed in $100 \mathrm{~mm}$ dishes using $5 \mu \mathrm{g}$ of plasmid DNA and Lipofectamine (Invitrogen, Gaithersburg, MD) according to manufacturer's protocol. For immunoprecipitations, transfected COS7 were lysed and subjected to immunoprecipitation using affinity-purified anti-tau and Protein A-Sepharose 4B (Amersham Biosciences, Piscataway, NJ) as previously described (Lee et al., 1998). After washing, protein-A Sepharose bound proteins were eluted and resolved by $8 \%$ SDS-PAGE. For direct analysis of transfected COS cell lysates, cells were harvested in $2 \times$ Laemmli sample buffer, boiled, and resolved by $8 \%$ SDS-PAGE. Transfer to polyvinylidene difluoride membranes (Immobilon-P; Millipore, Bedford, MA) and visualization using enhanced chemiluminescence (ECL) detection was according to manufacturer's instructions (PerkinElmer Life Sciences, Boston, MA). Antibodies used for probing blots were tau46.1, tau14, tau1, 5A6 (Johnson et al., 1997), tau5 (Carmel et al., 1996), anti-phosphotyrosine monoclonal 4G10 (Upstate Biotechnology, Charlottesville, VA), or anti-fyn monoclonal (Transduction Laboratories, Lexington, KY). Secondary antibody was sheep anti-mouse Ig, horseradish peroxidase linked $\mathrm{F}\left(\mathrm{ab}^{\prime}\right)_{2}$ fragment (Amersham Biosciences).

NIH3T3 cells were seeded onto $12 \mathrm{~mm}$ glass coverslips for immunofluorescence analysis. Transfections of seeded cells were performed using Lipofectamine Plus according to manufacturer's protocol. Cells were fixed with $0.3 \%$ glutaraldehyde as previously described (Lee and Rook, 1992 ) except with the use of $0.1 \%$ instead of $0.5 \%$ NP- 40 . Secondary antibodies were obtained from Jackson ImmunoResearch (West Grove, PA) or Molecular Probes (Eugene, OR). For visualizing total tau, either an affinity-purified anti-tau or the CR antibody preparation (described below) were used at 1:1000. Both labeled tau and tau-fyn transfected cells identically. The monoclonal 9G3 (described below) was used at $\sim 0.5$ $\mu \mathrm{g} / \mathrm{ml}$.

SH-SY5Y cells. Growth of SH-SY5Y cells in RPMI with 8\% serum conditions and GST-fyn SH3 fusion protein binding assay were performed as previously described (Lee et al., 1998). Briefly, SH-SY5Y cell lysate prepared from a $100 \mathrm{~mm}$ plate of cells $(\sim 80 \%$ confluency) was reacted with $30 \mu \mathrm{g}$ of purified GST-fyn SH3 fusion protein preadsorbed to glutathione sepharose beads (Amersham Biosciences). Incubation was performed for $1 \mathrm{hr}$ at $4^{\circ} \mathrm{C}$ and beads were washed in wash buffer $(0.5 \%$ Triton X-100, $50 \mathrm{~mm}$ Tris, $\mathrm{pH} 7.5$, and $150 \mathrm{~mm} \mathrm{NaCl}$ ). Bound proteins were separated by SDS-PAGE and subjected to immunoblotting. SHSY5Y cell lysates used in blots displayed in Figure $4, A$ and $B$, contained $\sim 1 \%$ of the lysate prepared from a $100 \mathrm{~mm}$ plate of cells.

Anti-PY18 polyclonal serum preparation. A rabbit polyclonal antiserum was prepared against a phosphorylated synthetic tau peptide EDHAGTpYGLGDRK (residues 12-24) (Research Genetics Inc., Huntsville, AL). To increase specificity, the antiserum was subjected to two steps of affinity purification. The antiserum was first affinity purified using a column containing the phosphorylated peptide. Eluted antibodies were then passed through a second column containing non-phosphorylated peptide to adsorb nonphosphorylation-specific antibodies. The flow through fraction contained antibodies that specifically reacted to the phosphorylated tau epitope. This antibody preparation was named "anti-PY18" and was used at 1:1000 for immunoblotting.

Antibodies adsorbed to the second column were also eluted. These antibodies reacted to the nonphosphorylated tau peptide (residues 1224) and were therefore directed against the tau sequence surrounding tyrosine 18 but did not require phosphotyrosine to react. This antibody preparation was named "CR" and was used at 1:1000 for immunocytochemistry.
Monoclonal antibody preparation and characterization. Monoclonal antibodies were prepared against a phosphorylated synthetic tau peptide EDHAGTpYGLGDRK (residues 12-24) (University of Iowa Hybridoma Facility, Iowa City, IA). Mice were immunized with the KLH-coupled peptide using CpG 1826 (Hybridon, Milford, MA) as adjuvant (Davis et al., 1998). Screening of hybridomas by ELISA was performed as described by Jicha et al. (1997), using biotinylated phosphorylated peptide bound to neutravidin-coated microtiter plates. Peptides were purchased from Multiple Peptide Systems (San Diego, CA). Reacting monoclonals were further characterized by ELISA using the nonphosphorylated peptide. Of the phosphorylation-specific clones, clone 9G3, whose isotype was IgG2a, was selected for further characterization. Purified 9G3 antibody was obtained by Protein-G HiTrap purification (Amersham Biosciences). For blots, $9 \mathrm{G} 3$ was used at $0.05-0.2 \mu \mathrm{g} / \mathrm{ml}$.

The binding kinetics of tyrosine phosphorylated and nonphosphorylated tau peptide (residues 12-24) to monoclonal antibody 9G3 were monitored in real time using surface plasmon resonance with the BIAcore 3000 instrument (BIAcore AB, Uppsala, Sweden). The sensor chip (CM5; BIAcore $\mathrm{AB}$ ) was activated by 1:1 $N$-hydroxy succinimide and $\mathrm{N}$-ethyl- $\mathrm{N}^{\prime}$-(3-dimethilaminopropyl)-carbodiimide hydrochloride (Amersham Biosciences) according to manufacturer's protocol. Seventyfive microliters of recombinant Protein LA (Sigma, St. Louis, MO) at a concentration of $100 \mu \mathrm{g} / \mathrm{ml}$ in coupling solution ( $10 \mathrm{~mm}$ sodium acetate; $\mathrm{pH}$ 5.0) was immobilized on the activated sensor chip at a flow rate of 5 $\mu \mathrm{l} / \mathrm{min}$ using the amine coupling kit (BIAcore AB). Protein LA is an Ig binding protein (Svensson et al., 1998). Excess reactive carboxy methylated dextran on the CM5 sensor chip was then deactivated by $35 \mu \mathrm{l}$ of ethanolamine. All measurements were performed using HBS buffer (10 mм HEPES, pH 7.4, $0.15 \mathrm{~m} \mathrm{NaCl}, 3$ mm EDTA, and 0.005\% (v/v) Surfactant P20) at $25^{\circ} \mathrm{C} .30 \mu \mathrm{g} / \mathrm{ml}$ purified $9 \mathrm{G} 3$ antibody or the control mouse IgG2a, $\kappa$ (UPC-10; Sigma) were injected ( $15 \mu \mathrm{l}$ at $10 \mu \mathrm{l} / \mathrm{min}$ ) in sequence with different concentrations of phosphorylated or nonphosphorylated tau peptides (250, 500, and $1000 \mathrm{~nm}$ ) onto the Protein LA surface using the "Co-inject" method (BIAcore, 1999). In this method, the injection of a second sample (tau peptide) immediately follows the first (9G3 or IgG2a). Binding responses of the peptides to the control IgG2a surface were subtracted from the binding responses to the $9 \mathrm{G} 3$ surface before performing kinetic analysis. Equilibrium association and dissociation rate constants were calculated using the Langmuir (1:1) binding model using the BIAevaluation 3.0 software supplied by the manufacturer.

A control peptide corresponding to a p34cdc2 peptide (KVEKIGEGTYGVVY) with and without tyrosine phosphorylation at the GTYG motif (Pierce, Rockford, IL) was similarly tested for binding to 9G3.

In vitro phosphorylation of tau and microtubule binding assays. Tyrosine phosphorylated tau was prepared using fyn or src tyrosine kinase (Upstate Biotechnology) and Escherichia coli-synthesized tau (352 residue isoform) purified as previously described (Brandt and Lee, 1993). One microgram of $E$. coli-synthesized tau was incubated with $4 \mathrm{U}$ of fyn or src at $37^{\circ} \mathrm{C}$ for $30 \mathrm{~min}$ according to manufacturer's conditions $(40 \mu \mathrm{l}$ final volume). Control kinase reactions omitted either tau or fyn. For analysis of tyrosine phosphorylation, reactions were probed with phosphotyrosine-specific antibodies by immunoblotting. For microtubule binding assays, aliquots from the kinase reactions were used without further purification. Taxol-stabilized microtubules were prepared from phosphocellulose-purified tubulin (Cytoskeleton, Inc., Denver, CO). Microtubule binding was performed in a volume of $20 \mu \mathrm{l}$ by combining $0.25 \mu \mathrm{g}$ of kinased tau and $10 \mu \mathrm{g}$ of taxol-stabilized microtubules and incubating at $37^{\circ} \mathrm{C}$ for $30 \mathrm{~min}$. The reaction was layered onto a $50 \%$ sucrose cushion $(160 \mu \mathrm{l})$ (Lee et al., 1989) and centrifuged at 100,000 $\times$ $g$ at room temperature (RT) for $30 \mathrm{~min}$. Both supernatant and pellet were recovered for analysis by Western blotting.

Developmental mouse brain samples. Mouse brain lysates were obtained from embryonic day 18 (E18), $1 \mathrm{~d}, 3 \mathrm{~d}, 1$ week, 2 and 3 weeks, 1 month, 2-, 3-, 6-, and 12-month-old ICR mice. Thirty micrograms of protein was loaded per lane and immunoblotted with anti-PY18, 9G3, or a mixture of tau5-5E2 anti-tau monoclonal antibodies. Preparation of the blot was aided by RNWAY Laboratories (Seoul, Korea).

$A D$ brain samples and immunocytochemistry. Rapid autopsy brains from $\mathrm{AD}$ patients were harvested, and the temporal lobe was blocked and 


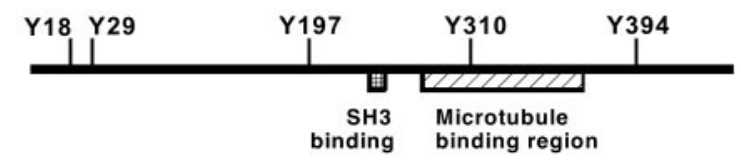
370

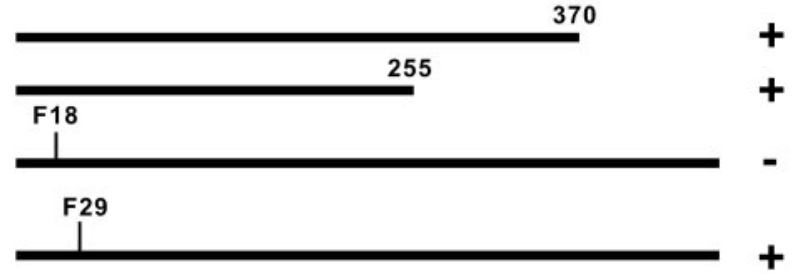

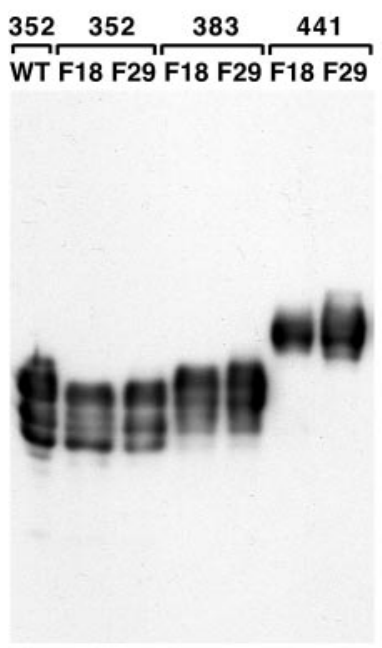

Anti-tau
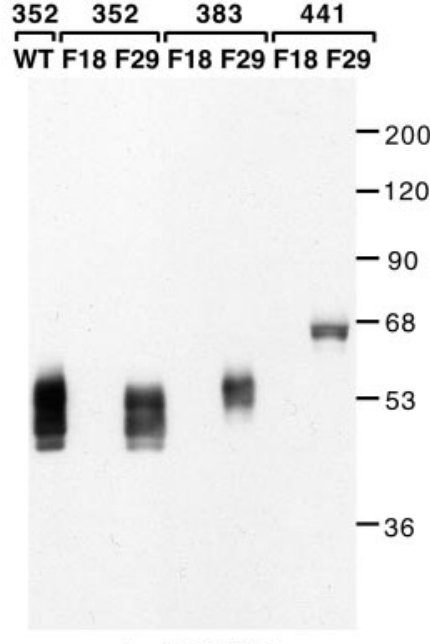

Anti-PY18
Figure 1. Identification of tyr18 as a site for tyrosine phosphorylation in tau. $A$, The schematic drawing shows the deletion constructs and point mutants tested for tyrosine phosphorylation (PY) in the presence of fyn using cotransfected COS7 cells. All constructs tested were derived from the 352 residue human tau isoform, shown at the top with the positions of tyrosines marked (numbering is according to the 441 adult tau isoform; the 441 adult isoform does not contain any additional tyrosines). Two ( terminal deletions and two point mutants were tested. After cotransfection with fyn into COS7 cells, tau was immunoprecipitated and tested for tyrosine phosphorylation with anti-phosphotyrosine. These data identified tyr18 as a tyrosine phosphorylation site in tau. $B$, An affinity-purified polyclonal antibody prepared against phosphorylated tyr18 (anti-PY18) was tested on COS7 cells cotransfected with fyn and various tau constructs. Lysates were probed with anti-PY18 (right panel) or a mixture of anti-tau monoclonal antibodies as control (left panel). A fyn control blot was also performed, showing that similar amounts of fyn were expressed in each transfection (data not shown). Mutants of three tau isoforms (amino acid lengths indicated) were tested. Mutations converted either tyr18 to phe18 (F18) or tyr29 to phe29 (F29). WT is wild-type tau. Despite the presence of tau in each transfection, F18 mutants did not react with anti-PY18, whereas F29 mutants did.

immersion-fixed in ice-cold 4\% paraformaldehyde in $0.1 \mathrm{M}$ PBS for 24-48 hr. Fixed slabs containing the hippocampus and adjacent temporal cortices were cut into $50-\mu \mathrm{m}$-thick sections on a freezing sliding microtome and stored in cryostorage until processed. Antibodies used were AT8 (1:1000; Innogenetics, Gent, Belgium), 9G3 (25 ng/ml), and CR (1:1000). Sections from five AD brains were examined, with ages ranging from 67 to 87 . No qualitative differences in 9G3 labeling were noted between cases.

Free-floating sections were processed for immunohistochemistry as previously described (Van Hoesen and Solodkin, 1993) with slight modifications. The sections were quenched with $0.1 \% \mathrm{H}_{2} \mathrm{O}_{2}$ in $0.1 \mathrm{M}$ PBS containing $0.4 \%$ Triton X-100 for $20-30 \mathrm{~min}$. After washing in $0.1 \mathrm{M}$ PBS, the sections were blocked with 5\% normal goat serum containing $0.4 \%$ Triton X-100 in $0.1 \mathrm{M}$ PBS for $1 \mathrm{hr}$ at RT. After the blocking step, the sections were incubated with primary antibody overnight at $4^{\circ} \mathrm{C}$. After washing, sections were incubated with biotinylated goat anti-mouse secondary antibody (1:500; Vector Laboratories, Burlingame, CA), washed then incubated with an avidin-biotin peroxidase complex (ABC Elite kit; Vector Laboratories) diluted 1:200 in $0.1 \mathrm{M}$ PBS containing $0.4 \%$ Triton $\mathrm{X}-100$. After rinsing, $0.03 \%$ 3,3'-diaminobenzidine (DAB) with $0.25 \%$ nickel ammonium sulfate in $0.1 \mathrm{M}$ PBS containing $0.01 \% \mathrm{H}_{2} \mathrm{O}_{2}$ was used for 5-10 min. Sections incubated in parallel without primary antibody failed to display any specific staining. Sections were rinsed in $0.1 \mathrm{M}$ PBS and mounted on gelatin-coated slides, dehydrated through graded ethanol, cleared in xylene, and coverslipped with cytoseal 60 (Richard-Allan Scientific, Kalamazoo, MI). For immunofluorescence staining, after primary antibody incubation, sections were incubated with Alexa 488 labeled anti-mouse (Molecular Probes) and Texas Red-labeled anti-rabbit (Jackson ImmunoResearch). Sections were mounted with Vectashield (Vector Laboratories) and visualized using the 1034 Bio-Rad (Hercules, CA) confocal system and Nikon E600 microscope. Serial optical sections were collected at 1 or $1.5 \mu \mathrm{m}$ steps, and series of $24-32$ sections were collected. Projections shown in Figure 6 were created using Confocal Assistant (version 4.02; T. C. Brelje).

Paired helical filament preparations. Paired helical filaments (PHFs) were prepared from temporal or frontal lobes of brains of four AD patients (F82, M86, M78, and M80 y/o, postmortem interval between 3.5 and $8 \mathrm{hr}$; mean, $5.8 \mathrm{hr}$ ) as described earlier (Ksiezak-Reding and Wall, 1994) with minor modifications. Briefly, $10 \mathrm{gm}$ of tissue were homogenized in five volumes of buffer A containing (in mM): $20 \mathrm{MES} / \mathrm{NaOH}, \mathrm{pH}$ $6.8,80 \mathrm{NaCl}, 1 \mathrm{MgCl}_{2}$, 2 EGTA, $0.1 \mathrm{EDTA}, 10 \mathrm{NaF}, 1$ sodium orthovanadate, and 0.2 PMSF. The homogenate was centrifuged $(20 \mathrm{~min}, 27,000 \times$ $g$ ), and the pellet was re-homogenized in buffer B, containing $10 \mathrm{~mm}$ MES/NaOH, pH 7.4, $0.8 \mathrm{~m} \mathrm{NaCl}, 10 \%$ sucrose, 1 mм EGTA, 10 mм NaF, $1 \mathrm{~mm}$ sodium orthovanadate, and $0.2 \mathrm{~mm}$ PMSF, and centrifuged as above. The supernatant was incubated with sarcosyl (1\% final concentration) for $1 \mathrm{hr}$ at RT or overnight at $4^{\circ} \mathrm{C}$. The sarcosyl mixture was then centrifuged $(2 \mathrm{hr}, 100,000 \times g)$. The pellet, which was highly enriched in both dispersed and aggregated PHFs, was resuspended in $10 \mathrm{~mm}$ MES/ $\mathrm{NaOH}, \mathrm{pH} 7.4$, and $1 \mathrm{~mm}$ sodium orthovanadate and subjected to discontinuous sucrose gradient as described (Ksiezak-Reding and Wall, 1994) but adding $1 \mathrm{~mm}$ sodium orthovanadate to all buffers. In the present studies, both sucrose gradient fractions "A2" and "AL2" were used. A2 contained highly purified and nonaggregated sarcosyl-insoluble PHFs. PHFs in the A2 fraction were filamentous (PHF filaments) as examined by electron microscopy and could be resolved into individual PHF tau polypeptides (62-68 $\mathrm{kDa}$ ) by SDS-PAGE. A2 fraction was used for both Western blot analysis and immunogold EM studies. AL2 contained highly purified and aggregated PHFs that were sarcosyl- and SDSinsoluble. Clusters and bundles of filaments were detected in this fraction by electron microscopy. AL2 was used for immunogold EM studies.

Immunogold labeling of PHFs was performed as described earlier (Takahashi et al., 2002) using anti-phosphotyrosine monoclonal antibody (mAb) PY20 (Transduction Laboratories, Lexington, KY) and $10 \mathrm{~nm}$ colloidal gold particles (Amersham Biosciences). Samples were examined using a JEOL 100CX electron microscope.

Phosphotyrosine phosphatase treatment of blots. T-cell protein tyrosine phosphatase (New England Biolabs, Beverly, MA) was used for phosphotyrosine phosphatase treatment. Blots were incubated with $20 \mathrm{U} / \mathrm{ml}$ phosphatase in the reaction buffer $(25 \mathrm{~mm}$ Tris/ $\mathrm{HCl}, \mathrm{pH} 7.0,50 \mathrm{~mm}$ $\mathrm{NaCl}, 2 \mathrm{~mm}$ EDTA, $5 \mathrm{~mm}$ dithiothreitol, $0.01 \%$ Tween 20, and $1 \mathrm{mg} / \mathrm{ml}$ BSA) for $4-24 \mathrm{hr}$ at $30^{\circ} \mathrm{C}$.

\section{Results}

\section{Development of antibody probes specific for a tyrosine} phosphorylated in tau

We have previously shown that in a transfected COS cell system, tau can be tyrosine-phosphorylated in the presence of fyn and that in SH-SY5Y cells, tau is tyrosine-phosphorylated (Lee et al., 1998). To determine the site of phosphorylation, we used the COS cell cotransfection system to express fyn and deletion fragments of tau. The immunoprecipitated tau fragments were immunoblotted with an anti-phosphotyrosine monoclonal 
Table 1. Kinetic constants for the interaction between $9 \mathrm{G3}$ and tau peptide (residues 12-24), obtained by the 1:1 Langmuir binding model

\begin{tabular}{lllr}
\hline & $k_{\mathrm{a}}\left(\mathrm{M}^{-1} \mathrm{sec}^{-1}\right)$ & $k_{\mathrm{d}}\left(\mathrm{sec}^{-1}\right)$ & $K_{\mathrm{D}}(\mathrm{M})$ \\
\hline 9G3 and tau non-phospho peptide & $30.7 \pm 0.2$ & $9.22 \pm 0.74 \times 10^{-6}$ & $3.33 \pm 0.2 \times 10^{6}$ \\
9G3 and tau phospho-peptide & $9.26 \pm 0.8 \times 10^{5}$ & $2.29 \pm 0.1 \times 10^{-6}$ & $3.0 \pm 0.27 \times 10^{-7}$ \\
\hline
\end{tabular}

antibody (4G10), showing that the phosphorylation site or sites lay in the $\mathrm{N}$-terminal 255 residues of tau, that contained three of the five tyrosines in tau (Fig. 1A). To examine the phosphorylation of individual sites, we mutated specific tyrosines to phenylalanine in full-length tau, and then similarly tested for tyrosine phosphorylation. The single substitution of tyr 18 to phe 18 eliminated the tyrosine phosphorylation of tau in the presence of fyn, thus identifying this residue as a tyrosine phosphorylation site in cells.

To further investigate tyrosine-phosphorylated tau, we prepared a rabbit polyclonal antibody, "anti-PY18," against a phosphorylated synthetic peptide of tau residues 12-24 (see Materials and Methods). To test the reactivity of anti-PY18 in immunoblots, we prepared tyrosine-phosphorylated tau by cotransfecting tau and fyn into COS cells. When wild-type tau was expressed with fyn, anti-PY18 reacted with proteins in the lysate that correspond to tau as identified by immunoblotting with anti-tau (Fig. $1 B$ ). When tau was mutated in tyr 18 and expressed with fyn, anti-PY18 reactivity was lost despite comparable levels of expression relative to the wild-type transfection. In contrast, when tyr29 was mutated, anti-PY18 reactivity was retained (Fig. $1 B$ ). These data indicate that anti-PY18 detects tyrosine phosphorylation of tau and are consistent with our mutational analysis identifying tyr 18 as a phosphorylated site. In addition, the testing of other tau isoforms (383 and 441 residue isoforms) indicated that alternative splicing of tau did not alter the site modified (Fig. $1 \mathrm{~B}$ ).

A monoclonal antibody against tyrosine phosphorylated tau residue 18 (9G3) was also prepared. To obtain direct quantitative data on its specificity, the association and dissociation kinetics of the interaction between 9G3 and tyrosine phosphorylated and nonphosphorylated tau peptides (residues 12-24) were followed by surface plasmon resonance. Different concentrations of each peptide were injected onto a surface coated with 9G3, using a surface coated with purified nonspecific mouse IgG2a as control. The kinetic constants are shown in Table 1. The equilibrium association constant $\left(K_{\mathrm{A}}=k_{\mathrm{a}} / k_{\mathrm{d}}\right)$ for the association between 9G3 and the phosphorylated tyr18 peptide was $4.04 \times 10^{11} \mathrm{M}^{-1}$, whereas the $K_{\mathrm{A}}$ between $9 \mathrm{G} 3$ and the nonphosphorylated peptide was $3.33 \times 10^{6} \mathrm{M}^{-1}$. This indicates that $9 \mathrm{G} 3$ has a high degree of specificity for the phosphorylated sequence. The dissociation constant $\left(K_{\mathrm{D}}=k_{\mathrm{d}} / k_{\mathrm{a}}\right)$ of $2.48 \times 10^{-12} \mathrm{M}$ for the interaction between $9 \mathrm{G} 3$ and the phosphorylated tyr 18 peptide indicates a high affinity of the antibody for the phosphorylated residue. As further characterization of the specificity of the antibody, we tested 9G3 for reactivity against a control tyrosine phosphorylated $\mathrm{p} 34 \mathrm{cdc} 2$ peptide that contained a known fyn phosphorylation site. The surface plasmon resonance response was below baseline, precluding any kinetic analysis. This indicated that the reactivity of 9G3 against generic phosphotyrosine was extremely low.

The utility of 9G3 to differentiate between phosphorylated and nonphosphorylated tau in immunocytochemistry protocols was demonstrated by immunofluorescence staining of 3T3 cells expressing either tau or tau and fyn. As expected, the presence of fyn was required for $9 \mathrm{G} 3$ reactivity (Fig. 2, compare $b$ with $d, f$ ). More importantly, the 9G3 staining pattern did not correspond
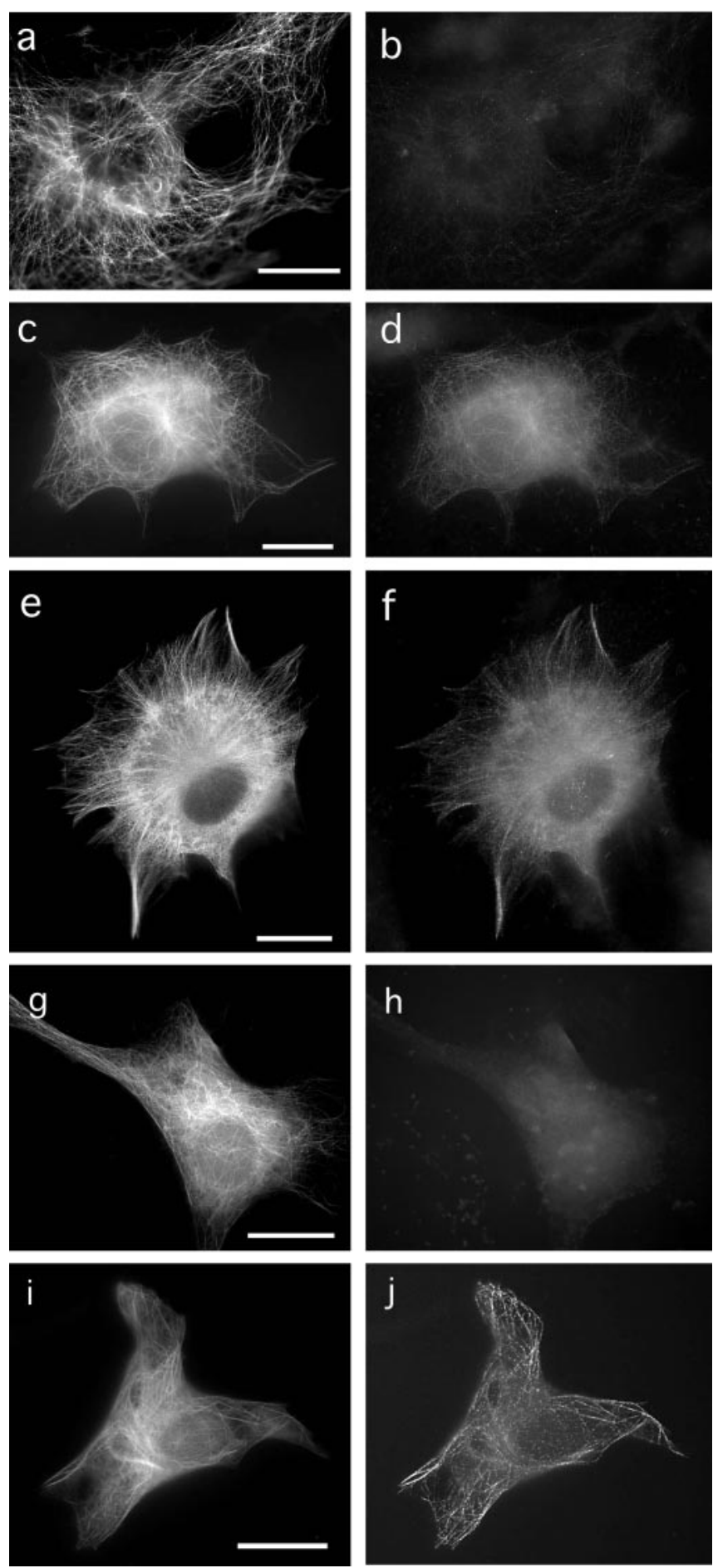

Figure 2. Reactivity of $9 \mathrm{G} 3$ to tau in transfected cells. A monoclonal antibody prepared against phosphorylated tyr $18(9 \mathrm{G} 3)$ was tested on $3 \mathrm{~T} 3$ cells transfected with tau $(a, b)$ or tau and fyn $(c-f)$. Cells were fixed and double stained with $C R$ for total tau $(a, c, e)$ and $9 \mathrm{G} 3$ for tyrosinephosphorylated tau $(b, d, f)$. 3T3 cells transfected with fyn and GFP-tau $(g, h)$ or fyn and tau-GFP $(i, j)$ were fixed and stained with 9G3. GFP is shown in $g$ and $i ; 9$ G3 labeling in $h$ and $j$. Note that $9 \mathrm{G} 3$ does not react to GFP-tau. Scale bar, $10 \mu \mathrm{m}$. 
to the total tau pattern, indicating that in staining fixed cells, 9G3 recognized a fraction of the total tau. This agreed with our previous finding (unpublished) that the efficiency of tyrosine phosphorylation of tau in fyn-tau cotransfected cells is $<100 \%$. Tyrosine-phosphorylated tau appeared as punctate staining seen along microtubules (Fig. $2 d, f$ ), suggesting that it is capable of associating with microtubules in cells. When a GFP-tau construct was used in the cotransfection, 9G3 reactivity was absent (Fig. 2h). Because GFP-tau contains GFP fused at the $\mathrm{N}$ terminus of tau in close proximity to tyr18, we surmised that the GFP fusion might either interfere with the phosphorylation of tyr 18 or with the reactivity of the antibody. In fact, when we used a tau fusion protein with GFP fused to the $\mathrm{C}$ terminus of tau (tau-GFP), coexpression of tau-GFP with fyn restored 9G3 reactivity (Fig. 2 j). To determine if GFP-tau was, in fact, tyrosine phosphorylated on tyr18, we assayed the phosphorylation by Western blotting using anti-PY18. We found that when GFP-tau and tau-GFP were expressed at comparable levels in the presence of fyn, both proteins were similarly phosphorylated (data not shown). Therefore, the accessibility of phosphotyr18 to $9 \mathrm{G} 3$ in fixed cells was affected by the N-terminal GFP fusion.

In summary, in developing probes specific for phosphorylated tyr 18, both polyclonal and monoclonal reagents were developed because it was anticipated that each reagent would have experimental limitations. The polyclonal preparation (anti-PY18) containing exclusively phosphorylation-specific antibodies would most likely also contain generic phosphotyrosine antibodies that could create background staining of irrelevant tyrosine phosphorylated proteins. The monoclonal reagent (9G3), although tau-specific, had some affinity for nonphosphorylated tau that could create phosphorylation-independent staining if high levels of tau were present. Therefore, we chose to use anti-PY18 primarily on blots, because the identity of staining proteins could be supported through other criteria such as molecular weight. 9G3 was most useful on tissue and fixed cell samples, where it was anticipated that the amount of tau in single cells would be relatively low compared with that in biochemical protocols involving tau overexpression.

\section{Phosphorylation of tyr 18 by fyn and its impact on microtubule binding}

The availability of a phosphorylation-specific antibody allowed us to demonstrate the phosphorylation of tau by fyn on tyr18 in vitro. After incubation of $E$. coli synthesized tau with fyn, tau became reactive to both anti-PY18 and 4G10 (Fig. 3, left). Identical results were observed for src (data not shown). This confirmed that tau is a substrate for src family non-receptor tyrosine kinases. In vitro tyrosine-phosphorylated tau was then tested for its ability to bind to taxol-stabilized microtubules, using nonphosphorylated tau as a control. After the incubation of tau with microtubules, centrifugation was used to separate microtubule bound tau (pellet) from unbound tau (supernatant). Pellets and supernatants were probed by both anti-tau and anti-PY18 (Fig. 3, right). Nonphosphorylated tau bound to microtubules with $\sim 50 \%$ efficiency (lanes 1 and 2), whereas tau from the kinase reaction appeared to have a similar binding efficiency of $\sim 50 \%$ (lanes 3 and 4), with tau being almost equally distributed between the supernatant and pellet. Because the stoichiometry of phosphate incorporation in the in vitro kinase reaction was not determined, we probed the same fractions with anti-PY18 and found that tyrosine-phosphorylated tau was similarly distributed between bound and unbound fractions (lanes 7 and 8). This suggested that tyrosine phosphorylation of tau by fyn did not largely alter the microtubule binding behavior of tau. This is consistent with the data from transfected cells showing the association of tyrosine-phosphorylated tau with microtubules (Fig. $2 d, f, j$ ).

\section{Presence of phospho-tyr18 in neuronal cells and in degenerating neurons}

To determine if tau tyr18 was phosphorylated in neuronal cells, anti-PY18 was used to probe lysates from human neuroblastoma (SH-SY5Y) cells. Two reactive species were revealed (Fig. 4A), with the upper species (indicated by the arrowhead) corresponding to endogenous tau in mobility. The lower species (indicated by the asterisk) was a cross-reactive non-tau protein with a mobility corresponding to that of tubulin. To confirm the identity of the upper species as tau, fyn-SH3 binding proteins were isolated from SH-SY5Y lysates using GST fusion protein-mediated binding assays. Our previous studies had shown that SH-SY5Y tau binds to GST-fyn-SH3. Using anti-PY18 to probe proteins binding to fyn SH3 confirmed that the upper band is tau (Fig. 4A); unlike tau, the cross-reactive protein did not bind to fyn $\mathrm{SH}$. The monoclonal 9G3 was also used to probe a lysate from SH-SY5Y cells. As a specificity control, 25-1000 ng of E. coli tau were probed in parallel. The monoclonal 9G3 reacted to a single species in the cell lysate without reacting to nonphosphorylated tau under the same conditions (Fig. $4 B$ ), thus confirming the phosphorylation of tau at residue 18 in neuronal cells.

The tyrosine phosphorylation of tau during brain development was examined in mouse by immunoblotting using both anti-PY18 and 9G3. The results indicated that tyrosinephosphorylated tau was most abundant at E18 and $1 \mathrm{~d}$ postnatal (Fig. 4C). Although still present at $3 \mathrm{~d}$ and 1 week postnatally, it no longer appeared after 2 weeks (oldest time point examined was 1 year). This pattern of expression suggests that tyrosinephosphorylated tau has a role in early neuronal development and 


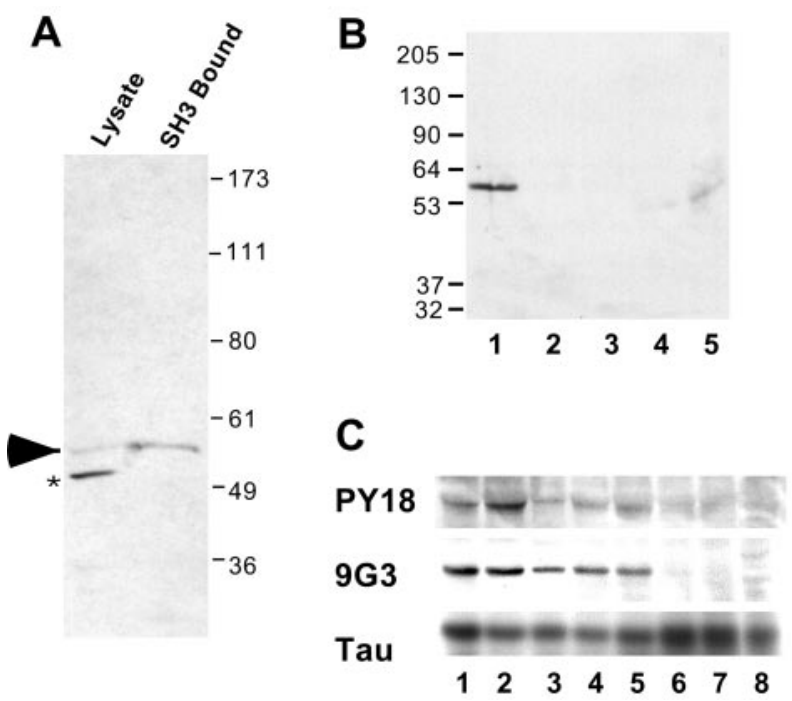

Figure 4. Tyrosine-phosphorylated human tau tyr18 is present in neuronal tau. A, SH-SY5Y cell lysate (left lane) and GST-fyn SH3 bound proteins from SH-SY5Y cells (right lane) were immunoblotted with anti-PY18. Arrow marks SH-SY5Y tau; asterisk protein was a cross-reacting species. B, SHSY5Y cell lysate (lane 1 ) and 25, 100, 400, and $1000 \mathrm{ng}$ of $E$. coli tau (lanes 2, 3, 4, and 5, respectively) were immunoblotted with monoclonal antibody 963 . C, Mouse brain ( $30 \mu \mathrm{g}$ of tissuelysate per lane) was probed with anti-PY18, $9 \mathrm{G} 3$, or a mixture of tau monoclonal antibodies $5 \mathrm{E} 2$ and tau5. Lysates werefrom (1) E18, (2) 1 d postnatal, (3) 3 d postnatal, (4) 1-week-old, (5) 2-week-old, (6) 3-week-old, (7) 1-month-old, and (8) 1-year-old mouse. Probing of lysates from 2-, 3-, and 6-month-old mice showed data similar to that of the 1-month-old mouse.

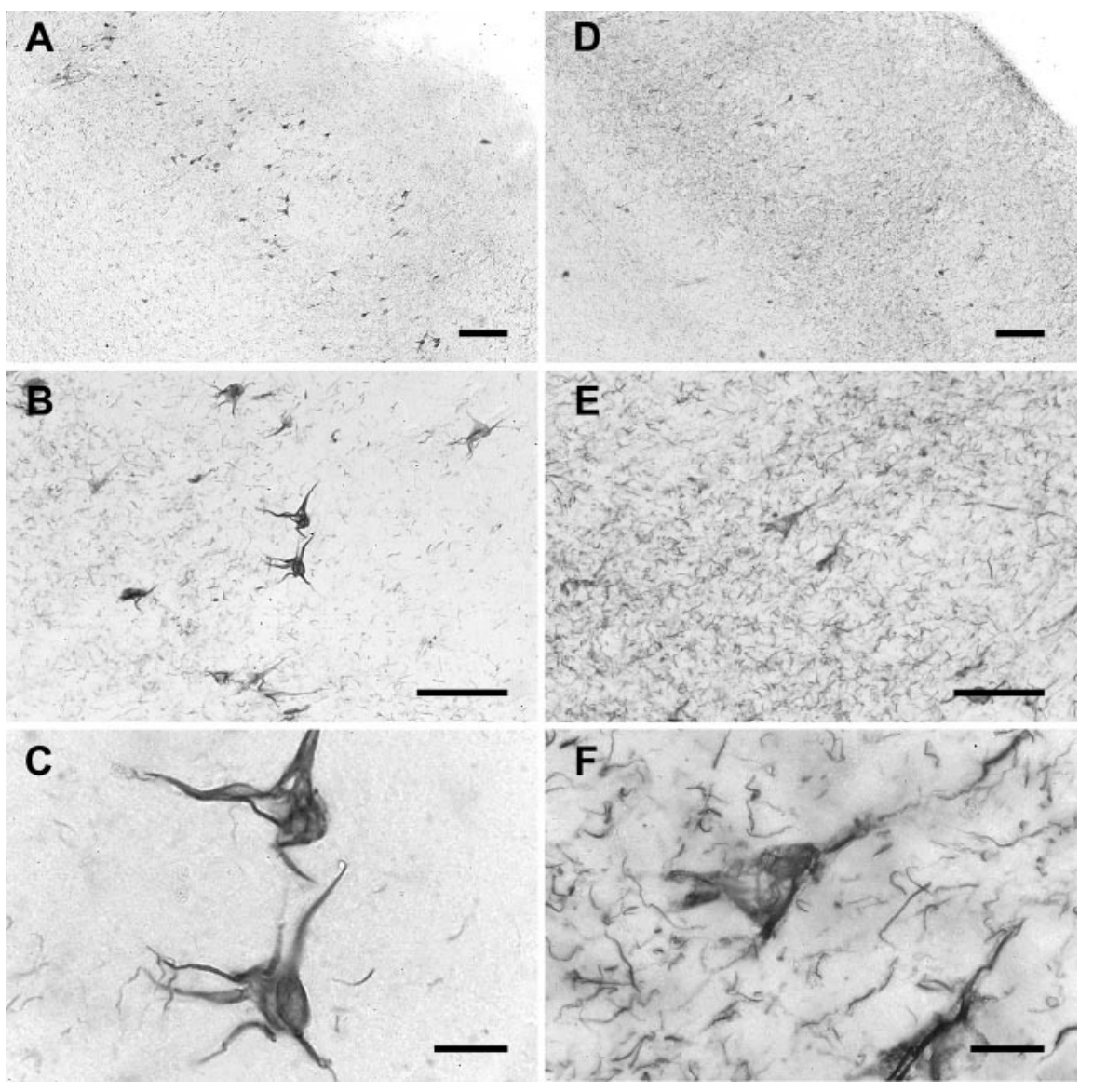

Figure 5. AD brain tissue contains tau phosphorylated at tyr18. Sections from the entorhinal cortex of AD brain were labeled with either $9 \mathrm{G3}$ (left) or AT8 (right) followed by development using DAB and nickel ammonium sulfate (see Materials and Methods). Magnification in each left panel is identical to that of the adjacent right panel. Scale bars: $A, D, 200 \mu \mathrm{m} ; B, E, 100 \mu \mathrm{m} ; C, F, 20$ $\mu \mathrm{m}$. Note that AT8 labeled neuropil threads and dystrophic neurites, whereas $9 \mathrm{G} 3$ did not. is consistent with the role of fyn in neuronal development (Grant et al., 1992).

Interestingly, several serines and threonines that are highly phosphorylated in rat fetal tau (Watanabe et al., 1993) are also downregulated in adult. In addition, several of these sites are also phosphorylated in human fetal tau and correspond to sequences that are highly phosphorylated in the neurofibrillary tangles of AD brain (e.g., the Ser198-Ser208 region that reacts with AT8 and the ser396-ser404 region that reacts with PHF-1) (Kanemaru et al., 1992; Bramblett et al., 1993; Goedert et al., 1993). Because phosphorylated tyr 18 has a similar developmental profile, we tested AD brain tissue for the presence of phosphorylated tyr 18 .

Temporal cortex sections from AD brain containing the entorhinal and hippocampal formation were probed with 9G3. The staining pattern was compared with that of a proven PHF antibody, AT8. We found that 9G3 labeled neurofibrillary tanglebearing neurons in the entorhinal layer II islands in a manner indistinguishable from AT8 (Fig. 5, left 9G3, right AT8). In contrast to AT8 however, 9G3 did not label neuropil threads and dystrophic neurites. This suggested that phosphotyrosine residue 18 is present in only some PHF. This was further illustrated by immunofluorescent double labeling of brain sections using 9G3 and $\mathrm{CR}$, an antibody affinity-purified using the nonphosphorylated peptide containing tyr18 (see Materials and Methods). Confocal microscopy showed that CR labeling did not necessarily coincide with 9G3 labeling (Fig. 6, top row), suggesting that although tyrosine-phosphorylated tau existed in neurofibrillary tangles, not all of the neurofibrillary tangles had phosphotyrosine. Close inspection of several series of $9 \mathrm{G} 3$ and $\mathrm{CR}$ double-labeled sections revealed that the intensity of 9G3 labeling often "peaked" at a different section relative to the CR labeling. Projections integrating the signals from several series of z-sections (Fig. 6, bottom panels) suggested that 9G3 labeling was less abundant than CR in distal regions. Therefore, the staining patterns of the two probes are distinct, suggesting that there is spatial specificity of tyrosine phosphorylation within the neuron. These data further support the specificity of 9G3 and indicate that tau phosphorylated at residue 18 is present in neurofibrillary tangles in degenerating neurons.

To demonstrate on a biochemical level that PHF tau polypeptides contained tyrosine-phosphorylated tau, PHF preparations were probed with either $4 \mathrm{G} 10$ or anti-PY18 on immunoblots. Both tyrosine phosphorylation-specific probes labeled PHF tau polypeptides (Fig. 7A, lanes 2 and 4); we were able to detect $4 \mathrm{G} 10$ or anti-PY18 reactivity in three different PHF preparations tested. In addition, the reactivity of anti-PY18 decreased to $61 \pm$ $8 \%(\mathrm{SD}, n=3)$ after treatment with a phosphotyrosine phosphatase (Fig. 7A, lanes 5 and 6). As further confirmation, PHF filaments, examined by electron microscopy in four AD brains with short postmortem interval (mean $<6 \mathrm{hr}$ ), showed immunogold labeling with anti- 

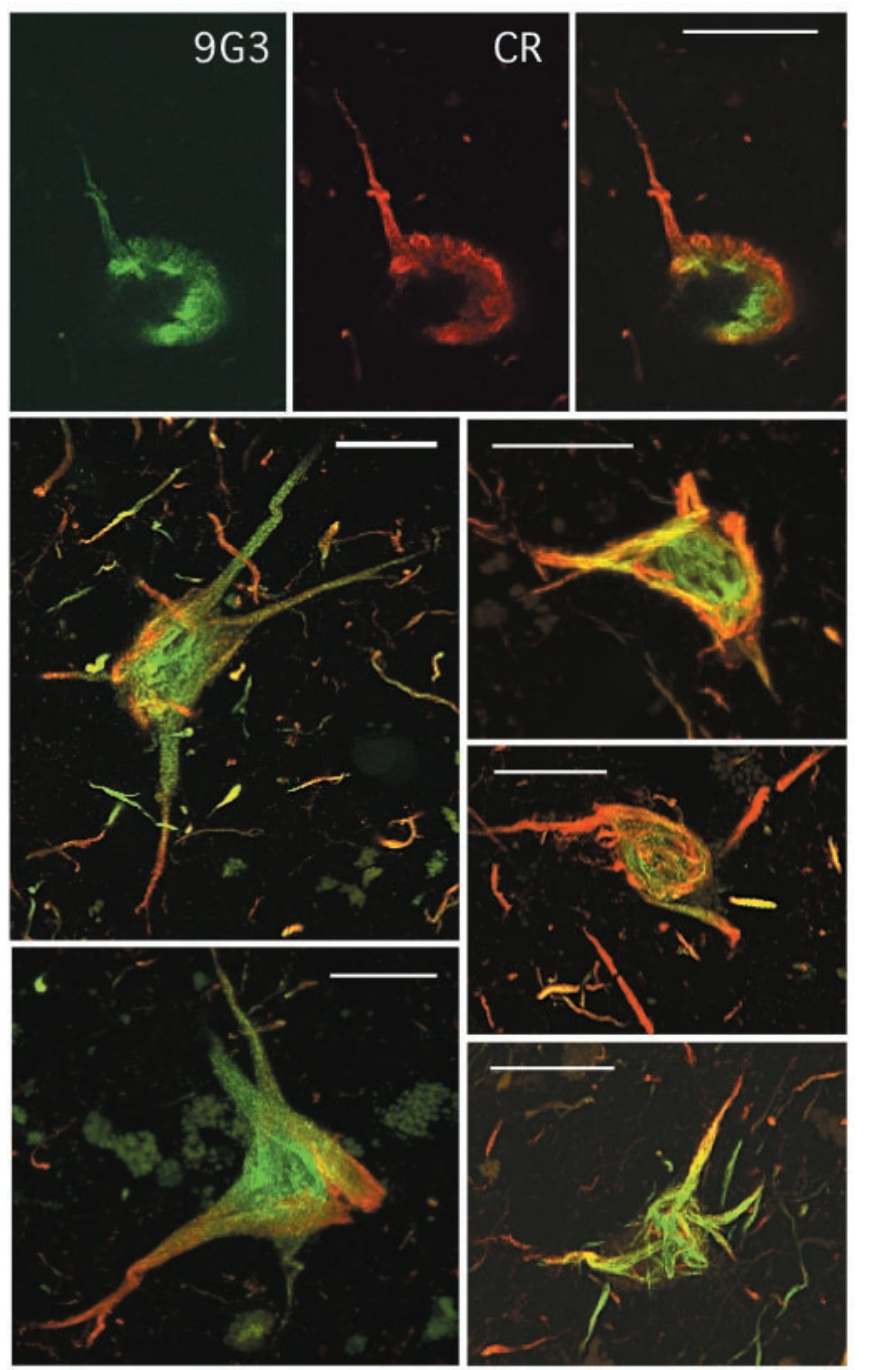

Figure 6. Degenerating neurons from the entorhinal cortex of AD brain. Top row shows a single optical section of a degenerating hippocampal neuron double labeled with CR and $9 \mathrm{G} 3$ and visualized by double immunofluorescence confocal microscopy. CR labeling was detected by Texas Red and $9 \mathrm{G} 3$ by Alexa 488 (see Materials and Methods) with the rightmost panel showing the merged images. Panels below show the merged projections for five neurons. The projections were created from series of 24-32 serial sections collected at either 1 or $1.5 \mu \mathrm{m}$ steps. Scale bars, $20 \mu \mathrm{m}$.

phosphotyrosine antibody (Fig. 7B). Both nonaggregated (A2) and aggregated (AL2) insoluble filaments showed labeling.

\section{Discussion}

Our identification of tyr 18 as the only tyrosine in tau phosphorylated by fyn in a transfected cell system is consistent with the known canonical substrate sequence determined for fyn (ETYG) (Dente et al., 1997). Of the five tyrosines in tau, tyr 18, located in the sequence GTYG, bears the highest homology to ETYG. Our previous studies had shown that tau interacts with the $\mathrm{SH} 3$ domain of fyn through a PXXP motif located in the middle of tau (pro233-pro236). Therefore, phosphorylation of tau at tyr 18 by fyn is likely to involve the folding back of the $\mathrm{N}$ terminus of tau toward its proline-rich area to direct residue 18 to the catalytic site of fyn. Although the presence of GFP at the $\mathrm{N}$ terminus did not inhibit the phosphorylation of tau by fyn, it appeared capable of rendering the resulting phospho-tyr18 nonreactive to $9 \mathrm{G} 3$ in fixed cells (Fig. $2 h$ ). The ability of the GFP fusion to alter this

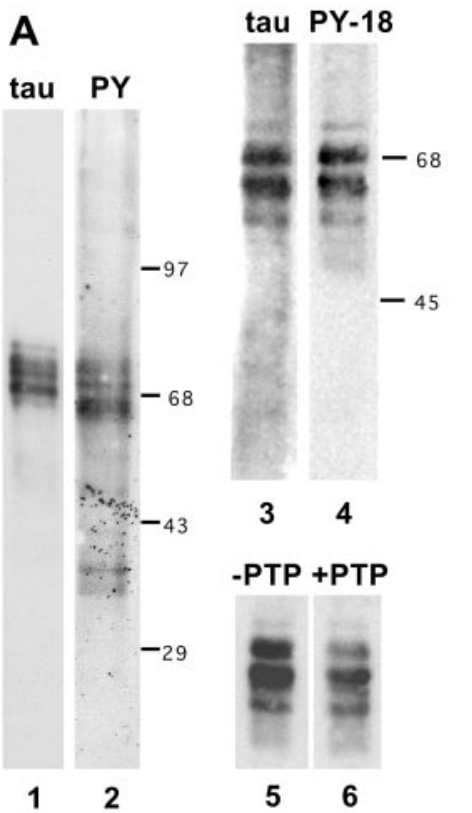

B

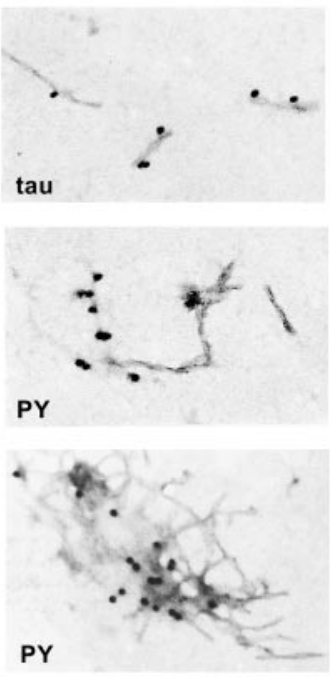

Figure 7. Sarcosyl-insoluble PHFs contain tyrosine-phosphorylated PHF tau. A, Two micrograms of PHFs were probed with anti-tau (lane 1) or anti-phosphotyrosine mAb4G10 (lane 2); $0.6 \mu \mathrm{g}$ PHFs were probed with anti-tau (lane 3) or anti-PY18 (lane 4); $0.6 \mu \mathrm{g}$ PHFs were probed with anti-PY18 after the membrane was incubated with phosphotyrosine-specific protein phosphatase (lane 6). Mock incubation without phosphatase was similarly probed (lane 5). B, PHFs were labeled with PY20 and $10 \mathrm{~nm}$ gold-labeled anti-mouse. Labeled filaments were visualized by electron microscopy. Control labeling of the preparation was by 46.1 (top panel). Middle and bottom panels show labeling of nonaggregated (A2) and aggregated (AL2) PHF preparations, respectively (see Materials and Methods).

property of tau presents a cautionary note toward the use of tau GFP fusions.

Because the phosphorylation of tau on various serines and threonines affects its association with microtubules, it has often been hypothesized that in neurodegenerative disease, phosphorylation of tau contributes to neurodegeneration through the destabilization of microtubules. In investigating the tyrosine phosphorylation of tau, we have determined that this modification appears to have little effect on the microtubule binding properties of tau. However, in neuronal cells, the tyrosine phosphorylation of tau may be directly or indirectly related to phosphorylation at serine or threonine. The tyrosine phosphorylation of tau may indicate the presence of activated src family tyrosine kinases that can also activate serine-threonine kinases capable of phosphorylating tau, or, the tyrosine phosphorylation of tau may indicate the relocalization of that tau to a specific cellular compartment where active kinases reside. Tau has been reported in lipid rafts (Klein et al., 2002), membrane microdomains that contain activated src family kinases, as well as serine-threonine kinases. Our phosphotyrosine-specific probes will aid in the investigation of possible relationships between tyrosine, serine, and threonine phosphorylation of tau.

The ability of PY18 to stain PHF preparations on blots and the ability of $9 \mathrm{G} 3$ to stain neurofibrillary tangles in situ together provide strong evidence that tau is tyrosine-phosphorylated on residue 18 during the neuropathological process. The absence of 9G3 staining of neuropil threads and dystrophic neurites suggests that there will be heterogeneity in the phosphorylation of PHFs as isolated from diseased brains. It appears that the abundance of phosphotyrosine in a PHF preparation may depend on the proportion of PHFs originating from neurofibrillary tangles versus 
those originating from extensions of the neuronal somata such as neuropil threads and dystrophic neurites. A preliminary finding based on an immunocytochemical method of quantitating neuropil threads has estimated that neuropil threads can account for $>90 \%$ of PHF neuropathology (Mitchell et al., 2000). Therefore, phosphotyrosine content of PHFs may be much less relative to the phosphoserine and phosphothreonine content. An additional variable is that the amount of neurofibrillary tangles relative to other tau lesions could also depend on the specific anatomical region of the brain sampled and the stage of the disease (Dickson et al., 1992; Ghoshal et al., 2002). These factors explain, in part, why it may be difficult to consistently detect phosphotyrosine in different PHF preparations (Williamson et al., 2002). In contrast, the staining of neurofibrillary tangles by $9 \mathrm{G} 3$ in brain sections was consistently noted in our present studies.

Based on immunocytochemistry, several differences between neurofibrillary tangles and neuropil threads have been previously described. In particular, using panels of antibodies spanning the entire tau molecule, several studies have reported that antibodies directed against the $\mathrm{N}$ terminus of tau stain neuropil threads and dystrophic neurites poorly (Dickson et al., 1992; Endoh et al., 1993; Bondareff et al., 1994; Ghoshal et al., 2002; Garcia-Sierra et al., 2003). Therefore, a likely explanation for the lack of 9G3 reactivity in these tau lesions is that the extreme $\mathrm{N}$ terminus of tau is absent, possibly because of proteolysis. Our staining of brain sections with the CR antibody confirmed this result (unpublished data). Nevertheless, the possibility that the $\mathrm{N}$ terminus was present but inaccessible to antibody has yet to be ruled out.

The differential labeling of neurofibrillary tangles within neurons using antibodies that recognize different phosphorylation states of tyrosine18 (Fig. 6) is the first evidence that abnormal phosphorylation of tau may be spatially regulated within the degenerating neuron. Differential phosphorylation of tau in normal neurons has been previously described (Papasozomenos and Binder, 1987; Mandell and Banker, 1996). Tyrosine phosphorylation of tau within the neuron could be regulated at the levels of (1) the interaction between tau and the SH3, perhaps by tau phosphorylation and/or alternative splicing (Zamora-Leon et al., 2001), (2) the activation of tyrosine kinases, or (3) the activation of protein phosphotyrosine phosphatases.

Recently, it has been reported that tau phosphorylated on tyr29 was upregulated in the presence of $\mathrm{A} \beta$ and was present in PHFs (Williamson et al., 2002). The identification of tyr29 as a phosphorylated site was based on the in vitro phosphorylation of tau by lck, a src family kinase found commonly in lymphocytes. Although we could rule out the phosphorylation of tyr29 by fyn in transfected cells, our phosphorylation-specific probes did not allow us to detect the possible phosphorylation of tyr29 by other tyrosine kinases in neuronal cells. At the same time, we recognize the presence of some level of generic phosphotyrosine antibodies in affinity-purified polyclonal antibody preparations (Fig. 4A) and acknowledge that the reactivity of such preparations to tau may involve phosphorylation at sites other than tyr 18 and 29 by kinases other than fyn and lck. Our hypothesis that tyr 18 is phosphorylated in PHF is strongly supported by the reactivity of monoclonal antibody $9 \mathrm{G} 3$ to fixed $\mathrm{AD}$ tissue. The surface plasmon resonance data for this monoclonal suggests that its affinity for the phosphorylated tau sequence is $\sim 10^{5}$ times higher than its affinity for the nonphosphorylated sequence with the $K_{\mathrm{D}}$ of the antibody being in the picomolar range. We also showed that 9G3 does not react to a tyrosine-phosphorylated peptide containing the fyn substrate sequence (ETYG), underscoring its specificity for the sequences around tyr 18 . As the sequences surrounding the other tyrosines in human tau do not bear resemblance to the tyr 18 area, it is unlikely that 9G3 might recognize a phosphotyrosine in human tau other than tyr18. However, our data does not address the possibility that our neurofibrillary tangle staining may, in part, result from the presence of another neuronal protein that contains a phospho-tyr18-like sequence. Therefore, appropriate caution should be exercised.

We have previously speculated that during neurodegeneration, if fyn were to become activated, a mitogenic or cellproliferative response might ensue, leading to the tyrosine phosphorylation of tau (Lee et al., 1998). Interestingly, tyrosinephosphorylated tau has also been reported in human prostate cancer cells (Sangrajrang et al., 1998), and it was previously found that tau could be tyrosine-phosphorylated in vitro by the oncogene v-fms, a src family tyrosine kinase expressed in human histiocytic lymphoma cells (Kim et al., 1991). Because cancer and oncogenes are associated with abnormal cell proliferation, these findings in non-neuronal cells may serve to link the tyrosine phosphorylation of tau to cell signaling pathways that turn on cell growth. Using in situ hybridization, it has been shown that AD brain contains neurons that are tetraploid (Yang et al., 2001). These data provide strong evidence for the hypothesis that the neuron is attempting a re-entrance into the cell cycle (for review, see Arendt, 2000; Herrup and Yang, 2001; Lu et al., 2003) and are consistent with the hypothesis that the degenerating neuron is recapitulating an early developmental state (Bramblett et al., 1993; Goedert et al., 1993). A role for fyn in development has been shown in fyn-deficient mice (Grant et al., 1992; Lowell and Soriano, 1996). In addition, fyn participates in the cell cycle (Yasunaga et al., 1996; Sette et al., 2002). Together with the data of Shirazi and Wood (1993) demonstrating the upregulation in fyn in $\mathrm{AD}$ brain, our present studies showing the presence of a fyn phosphorylated site in PHF tau further support a role for fyn in neuropathogenesis.

\section{References}

Arendt T (2000) Alzheimer's disease as a loss of differentiation control in a subset of neurons that retain immature features in the adult brain. Neurobiol Aging 21:783-796.

Bamberger ME, Harris ME, McDonald DR, Husemann J, Landreth GE (2003) A cell surface receptor complex for fibrillar beta-amyloid mediates microglial activation. J Neurosci 23:2665-2674.

BIAcore (1999) BIAcore 3000 Instrument Handbook. BIAcore: Uppsala, Sweden.

Bondareff W, Harrington C, Wischik CM, Hauser DL, Roth M (1994) Immunohistochemical staging of neurofibrillary degeneration in Alzheimer's disease. J Neuropathol Exp Neurol 53:158-164.

Bramblett GT, Goedert M, Jakes R, Merrick SE, Trojanowski JQ, Lee VM-Y (1993) Abnormal tau phosphorylation at Ser ${ }^{396}$ in Alzheimer's disease recapitulates development and contributes to reduced microtubule binding. Neuron 10:1089-1099.

Brandt R, Lee G (1993) Functional organization of microtubule-associated protein tau. Identification of regions which affect microtubule growth, nucleation, and bundle formation in vitro. J Biol Chem 268:3414-3419.

Carmel G, Mager EM, Binder LI, Kuret J (1996) Structural basis of monoclonal antibody Alz50's selectivity for Alzheimer's disease pathology. J Biol Chem 271:32789-32795.

Davis HL, Weeratna R, Waldschmidt TJ, Tygrett L, Schorr J, Krieg AM (1998) CpG DNA is a potent enhancer of specific immunity in mice immunized with recombinant hepatitis B surface antigen. J Immunol 160:870-876.

Dente L, Vetriani C, Zucconi A, Pelicci G, Lanfrancone L, Pelicci PG, Cesareni G (1997) Modified phage peptide libraries as a tool to study specificity of phosphorylation and recognition of tyrosine containing peptides. J Mol Biol 269:694-703.

Dickson DW, Ksiezak-Reding H, Liu WK, Davies P, Crowe A, Yen SH (1992) Immunocytochemistry of neurofibrillary tangles with antibodies to sub- 
regions of tau protein: identification of hidden and cleaved tau epitopes and a new phosphorylation site. Acta Neuropathol 84:596-605.

Endoh R, Ogawara M, Iwatsubo T, Nakano I, Mori H (1993) Lack of the carboxyl terminal sequence of tau in ghost tangles of Alzheimer's disease. Brain Res 601:164-172.

Garcia-Sierra F, Ghoshal N, Quinn B, Berry RW, Binder LI (2003) Conformational changes and truncation of tau protein during tangle evolution in Alzheimer's disease. J Alzheimers Dis 5:65-77.

Ghoshal N, Garcia-Sierra F, Wuu J, Leurgans S, Bennett DA, Berry RW, Binder LI (2002) Tau conformational changes correspond to impairments of episodic memory in mild cognitive impairment and Alzheimer's disease. Exp Neurol 177:475-493.

Goedert M, Jakes R, Crowther RA, Six J, Lubke U, Vandermeeren M, Cras P, Trojanowski JQ, Lee VM-Y (1993) The abnormal phosphorylation of tau protein at Ser-202 in Alzheimer disease recapitulates phosphorylation during development. Proc Natl Acad Sci USA 90:5066-5070.

Grace EA, Busciglio J (2003) Aberrant activation of focal adhesion proteins mediates fibrillar amyloid beta-induced neuronal dystrophy. J Neurosci 23:493-502.

Grant SG, O’Dell TJ, Karl KA, Stein PL, Soriano P, Kandel ER (1992) Impaired long-term potentiation, spatial learning, and hippocampal development in fyn mutant mice. Science 258:1903-1910.

Hall GF, Yao J, Lee G (1997) Human tau becomes phosphorylated and forms filamentous deposits when overexpressed in lamprey central neurons in situ. Proc Natl Acad Sci USA 94:4733-4738.

Herrup K, Yang Y (2001) Pictures in molecular medicine: contemplating Alzheimer's disease as cancer: a loss of cell-cycle control. Trends Mol Med 7:527.

Jicha GA, Lane E, Vincent I, Otvos Jr L, Hoffmann R, Davies P (1997) A conformation- and phosphorylation-dependent antibody recognizing the paired helical filaments of Alzheimer's disease. J Neurochem 69: 2087-2095.

Johnson GVW, Seubert P, Cox TM, Motter R, Brown, JP, Galasko D (1997) The t protein in human cerebrospinal fluid in Alzheimer's disease consists of proteolytically derived fragments. J Neurochem 68:430-433.

Kanemaru K, Takio K, Miura R, Titani K, Ihara Y (1992) Fetal-type phosphorylation of the $\tau$ in paired helical filaments. J Neurochem 58:1667-1675.

Kim H, Strong TV, Anderson SJ (1991) Evidence for tau expression in cells of monocyte lineage and its in vitro phosphorylation by v-fms kinase. Oncogene 6:1085-1087.

Klein C, Kramer EM, Cardine AM, Schraven B, Brandt R, Trotter J (2002) Process outgrowth of oligodendrocytes is promoted by interaction of fyn kinase with the cytoskeletal protein tau. J Neurosci 22:698-707.

Ksiezak-Reding H, Wall JS (1994) Mass and physical dimensions of two distinct populations of paired helical filaments. Neurobiol Aging 15:11-19.

Lambert MP, Barlow AK, Chromy BA, Edwards C, Freed R, Liosatos M, Morgan TE, Rozovsky I, Trommer B, Viola KL, Wals P, Zhang C, Finch CE, Krafft GA, Klein WL (1998) Diffusible, nonfibrillar ligands derived from Abeta1-42 are potent central nervous system neurotoxins. Proc Natl Acad Sci USA 95:6448-6453.

Lee G, Rook SL (1992) Expression of tau protein in non-neuronal cells: microtubule binding and stabilization. J Cell Sci 102:227-237.

Lee G, Neve RL, Kosik KS (1989) The microtubule binding domain of tau protein. Neuron 2:1615-1624.

Lee G, Newman ST, Gard DL, Band H, Panchamoorthy G (1998) Tau interacts with src-family non-receptor tyrosine kinases. J Cell Sci 111:3167-3177.

Lowell CA, Soriano P (1996) Knockouts of Src-family kinases: stiff bones, wimpy T cells, and bad memories. Genes Dev 10:1845-1857.

Lu KP, Liou YC, Vincent I (2003) Proline-directed phosphorylation and isomerization in mitotic regulation and in Alzheimer's disease. Bioessays 25:174-181.

Luo Y, Sunderland T, Wolozin B (1996) Physiologic levels of $\beta$-amyloid activate phosphatidylinositol 3-kinase with the involvement of tyrosine phosphorylation. J Neurochem 67:978-987.

Luo YQ, Hirashima H, Li YH, Alkon DL, Sunderland T, Etcheberrigaray R, Wolozin B (1995) Physiological levels of $\beta$-amyloid increase tyrosine phosphorylation and cytosolic calcium. Brain Res 681:65-74.
Mandell JW, Banker GA (1996) A spatial gradient of tau protein phosphorylation in nascent axons. J Neurosci 16:5727-5740.

Maness PF (1992) Nonreceptor protein tyrosine kinases associated with neuronal development. Dev Neurosci 14:257-270.

Mitchell TW, Nissanov J, Han LY, Mufson EJ, Schneider JA, Cochran EJ, Bennett DA, Lee VM, Trojanowski JQ, Arnold SE (2000) Novel method to quantify neuropil threads in brains from elders with or without cognitive impairment. J Histochem Cytochem 48:1627-1638.

Moore KJ, El Khoury J, Medeiros LA, Terada K, Geula C, Luster AD, Freeman MW (2002) A CD36-initiated signaling cascade mediates inflammatory effects of beta-amyloid. J Biol Chem 277:47373-47379.

Papasozomenos SC, Binder LI (1987) Phosphorylation determines two distinct species of Tau in the central nervous system. Cell Motil Cytoskel 8:210-226

Rapoport M, Dawson HN, Binder LI, Vitek MP, Ferreira A (2002) Tau is essential to beta-amyloid-induced neurotoxicity. Proc Natl Acad Sci USA 99:6364-6369.

Sangrajrang S, Denoulet P, Millot G, Tatoud R, Podgorniak MP, Tew KD, Calvo F, Fellous A (1998) Estramustine resistance correlates with tau over-expression in human prostatic carcinoma cells. Int J Cancer 77:626-631.

Sato N, Kamino K, Tateishi K, Satoh T, Nishiwaki Y, Yoshiiwa A, Miki T, Ogihara T (1997) Elevated amyloid $\beta$ protein $(1-40)$ level induces CREB phosphorylation at serine-133 via p44/42 MAP kinase (Erk1/2)dependent pathway in rat pheochromocytoma PC12 cells. Biochem Biophys Res Commun 232:637-642.

Sette C, Paronetto MP, Barchi M, Bevilacqua A, Geremia R, Rossi P (2002) Tr-kit-induced resumption of the cell cycle in mouse eggs requires activation of a Src-like kinase. EMBO J 21:5386-5395.

Shapiro IP, Masliah E, Saitoh T (1991) Altered protein tyrosine phosphorylation in Alzheimer's disease. J Neurochem 56:1154-1162.

Shirazi SK, Wood JG (1993) The protein tyrosine kinase, fyn, in Alzheimer's disease pathology. NeuroReport 4:435-437.

Svensson HG, Hoogenboom HR, Sjobring U (1998) Protein LA, a novel hybrid protein with unique single-chain Fv antibody- and Fab-binding properties. Eur J Biochem 258:890-896.

Takahashi M, Weidenheim KM, Dickson DW, Ksiezak-Reding H (2002) Morphological and biochemical correlations of abnormal tau filaments in progressive supranuclear palsy. J Neuropathol Exp Neurol 61:33-45.

Thomas SM, Brugge JS (1997) Cellular functions regulated by src family kinases. Annu Rev Cell Dev Biol 13:513-609.

Van Hoesen GW, Solodkin A (1993) Some modular features of temporal cortex in humans as revealed by pathological changes in Alzheimer's disease. Cereb Cortex 3:465-475.

Watanabe A, Hasegawa M, Suzuki M, Takio K, Morishima-Kawashima M, Titani K, Arai T, Kosik KS, Ihara Y (1993) In vivo phosphorylation sites in fetal and adult rat tau. J Biol Chem 268:25712-25717.

Williamson R, Scales T, Clark BR, Gibb G, Reynolds CH, Kellie S, Bird IN, Varndell IM, Sheppard PW, Everall I, Anderton BH (2002) Rapid tyrosine phosphorylation of neuronal proteins including tau and focal adhesion kinase in response to amyloid- $\beta$ peptide exposure: involvement of src family protein kinases. J Neurosci 22:10-20.

Wood JG, Zinsmeister P (1991) Tyrosine phosphorylation systems in Alzheimer's disease pathology. Neurosci Lett 121:12-16.

Yang Y, Geldmacher DS, Herrup K (2001) DNA replication precedes neuronal cell death in Alzheimer's disease. J Neurosci 21:2661-2668.

Yasunaga M, Yagi T, Hanzawa N, Yasuda M, Yamanashi Y, Yamamoto T, Aizawa S, Miyauchi Y, Nishikawa S (1996) Involvement of Fyn tyrosine kinase in progression of cytokinesis of B lymphocyte progenitor. J Cell Biol 132:91-99.

Zamora-Leon SP, Lee G, Davies P, Shafit-Zagardo B (2001) Binding of Fyn to MAP-2c through an SH3 binding domain. Regulation of the interaction by ERK2. J Biol Chem 276:39950-39958.

Zhang C, Lambert MP, Bunch C, Barber K, Wade WS, Krafft GA, Klein WL (1994) Focal adhesion kinase expressed by nerve cell lines shows increased tyrosine phosphorylation in response to Alzheimer's $\mathrm{A} \beta$ peptide. J Biol Chem 269:25247-25250. 